318 Stärkmehl der wilden Kastanie. - Pollenbestandth.

\title{
Naphtha und deren Gebrauch als Heilmittel.
}

Ueber das in Tscherkessien gegen die Cholera angewandte Steinöl, welches man in allen Stadien der Krankheit zu 15-20 Tropfen in einem Glase voll Wein verabreichen lässt, berichtet uns Ure Folgendes:

Dieses Oel entquillt einem thonigen Mergelboden in der Nähe von Derbend, nicht weit vom Goll Baku. Es hat eine blassgelbliche Farbe, ein spec. Gew. von 0,853 und sein Siedepunct liegt bei ungefahr $151^{\circ}$. Beim Destilliren erhielt man eine Flüssigkeit von 0,728 spec. Gew. und $80^{\circ}$ Siedepunct, die aber einen ganz andern empyreumatischen Geruch hatte. Dr. Ure spricht nebenbei die Meinung aus, dass sich in dem natürlichen Bergöle nicht dieselben Substanzen finden, wie in dem durch trockne Destillation der Steinkohlen erhaltenen Theere. Auch glaubt er, dass das Steinöl ein Product der Einwirkung des Wassers auf verkohlende Substanzen sei. Ure schlägt vor, das Steinöl als äusserliches Mittel durch Seife zu incorporiren, es hinterbleibt dann beim Waschen mit Wasser in den gereiniglen Poren der Haut so viel Oel, um es bei manchen Hautkrankheiten als sehr nützlich empfehlen zu können. (Pharm. Journ. and Transact. Vol. VIII. - Pharm. Centrbl. 1848. No. 53.)

B.

\section{Benutzung des Stärkmehls der wilden Kiastanie.}

Flandin glaubt, dass die wilde Kastanie ein wahres Nahrungsmittel werden wird, und hat Brod aus $1 \mathrm{Th}$. solcher Stäke und $3 \mathrm{Th}$. Weizenmehls, und Biscuit aus der unvermischten Stärke bereiten lassen, nachdem nämlich, wie schon früher einmal erwiahnt wurde, die Stärke mittelst kohlensauren Natrons von dem Bitterstoff befreit worden war. (Compt. rend. T.XXV11. - Pharm. Centrbl. 1818. No.55.)

B.

\section{Bestandtheile des Pollens.}

Nach der Behandlung des Pollens der rothen und weissen Lilie (Lilium candidum u. L. bulbiferum) successive mit Wasser, Weingeist und Aether hinterblieb das Pollenin als citronengelber Rückstand, der bis auf die folgenden, die Eigenschaften, welche davon angegeben sind, hatte. Es löste sich in Salpetersäure, ohne cine Veränderung zu erleiden, auf. Beim Erhitzen der salpetersauren Lösung schied sich die von Berzelius erwähnte Fellmateric an 